\title{
SOBRE A INTERPOLAÇÃO INTERIORIDADE E EXTERIORIDADE: A CRÍTICA DE BARBARAS À FENOMENOLOGIA DA VIDA DE HANS JONAS
}

\author{
On the interpolation interiority and exteriority: the criticism of Barbaras to the Hans Jonas \\ phenomenology of life
}

\begin{abstract}
Sobre la interpolación interioridad y exterioridad: la crítica de Barbaras a la fenomenología de la vida de Hans Jonas
\end{abstract}

JELSON ROBERTO DE OLIVEIRA

\begin{abstract}
Resumo: Pretende-se nesse artigo recuperar as bases da crítica de Renaud Barbaras à fenomenologia da vida de Hans Jonas tal como essas se apresentam na sua obra de 2008 Introduction à une phénoménologie de la vie. Para tanto, trata-se de levantar, entre outros argumentos, o problema da interpolação entre a interioridade e a exterioridade, o que teria permanecido, segundo Barbaras, como um problema não solucionado na tese de Jonas, o que levaria à impossibilidade de sua fenomenologia da vida, stricto senso. Embora não desenvolver-se-á a argumentação nesse trabalho, apontar-se-á, contudo, a possível resposta de Hans Jonas por meio do conceito de "vida expressiva", que indica a insistência na relação e na inter-compreensão como fenômeno mais originário da vida.
\end{abstract}

Palavras-chave: Interioridade; Exterioridade; Hans Jonas; Vida; Fenomenologia da vida.

\begin{abstract}
This paper aims to recover the basis of Renaud Barbaras's critique of the Hans Jonas's phenomenology of life life, as presented in his 2008 work Introduction à une phénoménologie de la vie. In order to do so, it is a question of raising the problem of the interpolation between interiority and exteriority, which would have remained, according to Barbaras, as an unresolved problem in Jonas's thesis, which would lead to the impossibility of his phenomenology of life, stricto senso. Although the argument will not be developed in this work, it will be pointed out, however, Hans Jonas's possible answer through the concept of "expressive life", which indicates the insistence on relation and inter-understanding as a phenomenon originating from life.
\end{abstract}

Keywords: Interiority; Exteriority; Hans Jonas; Life; Phenomenology of life.

Resumen: Se pretende en este artículo recuperar las bases de la crítica de Renaud Barbaras a la fenomenología de la vida de Hans Jonas tal como éstas se presentan en su obra de 2008 Introducción a la unión de la filosofía de la vie. Para ello, se trata de plantear, entre otros argumentos, el problema de la interpolación entre la interioridad y la exterioridad, lo que habría permanecido, según Barbaras, como un problema no solucionado en la tesis de Jonás, lo que llevaría a la imposibilidad de su fenomenología de la vida, stricto sentido. Aunque no se desarrollará la argumentación en ese trabajo, se señalará, sin embargo, la posible respuesta de Hans Jonas por medio del concepto de "vida expresiva", que indica la insistencia en la relación y en la intercomprensión como fenómeno más originario de la vida.

Palabras clave: Interioridad; Externalidad; Hans Jonas; Vida; Fenomenología de la vida.

Introdução

As ideias de Hans Jonas ocupam lugar importante na análise da fenomenologia da vida de Renaud Barbaras. $\mathrm{O}$ autor de The phenomenon of life se apresenta como um dos principais interlocutores do filósofo francês, seja quando reconhecemos sua importância no contexto geral da formulação teórica dessa fenomenologia, seja para quando lhe são dirigidas críticas e expostos os limites de seu pensamento. Seja como for, a proposta de Barbaras parte de uma intenção que não foi estranha a Jonas: pensar fenomenologicamente o sujeito a partir do vivo (ou como viver), aberto ao mundo por meio da percepção (caracterizado como desejo, um dos meios - Jonas se refere a esse dado como sentimento - segundo o qual os organismos se abrem para o mundo, ao lado do medo). Trata-se de encontrar um "sentido originário da vida mais profundamente do que a divisão entre estar vivo (leben) e ter experiência (erleben)" (Barbaras, 2013, p. 25) e que tanto se apresenta como medida de pertencimento radical ao mundo quanto de diferenciação em relação a ele, de tal forma que a vida é o tema central da fenomenologia: não há fenomenologia a não ser como fenomenologia da vida.

Por essa razão, Jonas está entre os sete autores centrais de Introduction à une phénoménologie de la vie (2008), constando entre aqueles que teriam contribuído com Barbaras para a reflexão em torno da relação entre vida e exterioridade, tema da segunda parte da obra de 2008. A problemática que aproxima Barbaras, afinal, de Jonas, é assim formulada: "qual é o sentido do ser da vida, partindo do pressuposto de que esta não encerra o sujeito vivo nele mesmo, senão que, ao contrário, o abre para a verdadeira 
exterioridade do mundo?" e, ainda, “como pensar a vida de tal modo que a intencionalidade da consciência se enraíze em sua vitalidade?" (Barbaras, 2013, p. 266). Essas duas perguntas encontram-se no centro da reflexão filosófica de Jonas a respeito do fenômeno da vida. Primeiro, porque ele propõe o pensamento sobre o vivo sempre em sua relação de exterioridade com o mundo, tanto por meio do conceito de liberdade, quanto de transcendência; e, segundo, porque Jonas coloca-se a pergunta sobre a relação entre aquilo que ele chama de espírito (mind) e matéria, no centro da formulação de sua reflexão sobre o fenômeno da vida, o qual, segundo Jonas, teria sido mal-interpretado tanto pelo dualismo quanto pelos dois movimentos pós-dualistas modernos, o idealismo e o materialismo.

\section{Sentido fenomenológico mínimo}

Embora coloque em questão o fato de que Jonas tenha, precisamente, uma fenomenologia ou, antes, pela indicação do subtítulo da obra jonasiana, uma biologia filosófica que o manteria atrelado às ciências da vida, Barbaras não deixa de notar o empenho de Jonas no enfrentamento dessas duas questões. Ao contrário, contudo, do que o próprio Jonas propõe, Barbaras ainda identifica traços de uma ontologia de raiz materialista na interpretação jonasiana, que interditaria o acesso a uma autêntica fenomenologia, fato que comprometeria a sua descrição a respeito da vida. Mesmo assim, o filósofo francês reconhece em Jonas a tentativa de sair da ontologia da morte que transformou a matéria inerte em medida de compreensão da vida, já que o morto, como regra geral da existência, passou a servir de modelo de tudo o que é conhecível. Além disso, Jonas logra enfrentar o problema por meio de uma reunião psicofísica a partir do testemunho ontológico dos seres humanos, a partir do qual seria possível compreender todo ser enquanto ser. E isso por meio de um antropomorfismo (que Barbaras também assume, sem muitas consequências teóricas, como biomorfismo), que Jonas resgata da ilegitimidade que lhe coube na história da filosofia moderna. Tratar-se-ia, nesse sentido, de um esforço fenomenológico precisamente porque parte de uma concepção da vida tal como ela nos ocorre para nós, ou seja, como ela é vivenciada pelos seres humanos, colocando precisamente entre parêntesis, aqueles pressupostos ontológicos com os quais a ciência moderna poderia ser descrita como a história da má-compreensão da vida como fenômeno. Barbaras, nesse caso, acompanha corretamente a proposta de Hans Jonas: foi preciso suspender a separação tradicional entre espírito e vida para recuperá-la "em si mesma, na plenitude de seu sentido e se sua extensão” (Barbaras, 2013, p. 268).

Barbaras identifica, contudo, tal estratégia como um sentido fenomenológico "mínimo", traduzida nessa pergunta pela "identidade" ou pelo "co-pertencimento" entre consciência e vida, algo que, segundo Barbaras, teria uma perspectiva tanto fenomenológica quanto científica. E é precisamente nisso que residira o problema: sendo científica, uma estratégia como essa poderia ser reconhecida fora do âmbito tradicional da ontologia da morte, algo que Jonas mesmo acusa a tradição científica ou, em outras palavras, teria legitimidade uma estratégia que acusa a ciência usando as próprias armas da ciência? Nesse sentido, aquele intento de realizar uma "biologia filosófica" seria precisamente o grande empecilho para que Jonas realizasse uma fenomenologia em sentido pleno. Para Barbaras, "partindo da vida tal como a descrevem os biólogos, seria definitivamente impossível chegar à existência humana em sua singularidade" (Barbaras, 2013, p. 273).

Aquela evidência fenomenológica segundo a qual nós, seres humanos, estamos na vida e somos vida e a partir dessa realidade somos capazes de conhecer todo o sistema do vivo, ou seja, todos os demais organismos, como se sabe, Jonas vai encontrar no evolucionismo, do qual se faz, ao mesmo tempo crítico e filiado. Crítico porque tal perspectiva científica ainda se mantém atrelada às premissas criticadas por Jonas na ciência moderna; filiado porque é pela via da evolução que é possível reconhecer o âmbito da unidade psicofísica que marca toda a história da vida, a qual, desde seus primórdios, ou seja, desde que a vida entrou no âmbito da existência, já apareceu não apenas em seus elementos materiais, mas trazendo "trazendo germinalmente prefiguradas" as condições espirituais, as quais se desenvolvem na forma de uma história da liberdade necessária que caracteriza a vida, desde o equilíbrio frágil do ser e do não-ser e, mais ainda, da ameaça do segundo sobre o primeiro.

Tal história da liberdade se revela, portanto, como uma característica essencial a partir da qual Jonas descreve o fenômeno da vida em suas etapas evolutivas desde o mais primitivo até o mais evoluído, passando por degraus que vão do metabolismo, passam pela sensação, pela emoção, pela percepção, pela mobilidade e atingem o grau mais notório da racionalidade. É precisamente por isso que, segundo Jonas, sua filosofia é "uma interpretação ‘ontológica' dos fenômenos biológicos” ou, nas palavras dele mesmo, uma "filosofia da vida", tem como objeto tanto a filosofia do organismo quanto a filosofia do espírito, conforme se lê já na introdução de The phenomenon of life. Nessa estratégia cabe ao filósofo descrever um fenômeno não por meio da pretensa objetividade que marca o método científico moderno, cujo prejuízo foi propriamente uma ontologia da morte, mas por meio de um reconhecimento de si mesmo como parte do fenômeno a ser analisado e, mais, de que é esse reconhecimento que estabelece a própria condição e viabilidade da tarefa a ser realizada: "o filósofo que contemple o grandioso panorama da vida em nosso planeta, e que se compreenda a si próprio como uma parte do mesmo" (PV 1 , 11). O testemunho da vida, nesse caso, ocorre como desafio ao método científico mo-

\footnotetext{
1 Citaremos nesse texto a tradução portuguesa da obra de 1966, vertida a partir da versão alemã, cujo título pede a ideia de fenomenologia da vida para acentuar o seu parentesco com a famosa obra de 1979, O princípio da responsabilidade. Nesse caso, usaremos a sigla $\mathrm{PV}$ para $O$ princípio vida; PL para a versão originária The Phenomenon of life; PE para Philosophical Essays; M para Memorias.
} 
derno, cujas premissas não se compatibilizam com a tentativa de descrição do fenômeno a ser estudado, o que legitima e exige o uso de outra "ferramenta” teórica, fornecida pela fenomenologia.

Nesse caso, trata-se de reconhecer, como Barbaras mesmo o faz, que as diferenças biológicas entre as espécies (tal como reconhecidas pelo evolucionismo) não quebram a corrente vital que unifica todos os seres vivos como pertencentes ao fenômeno da vida, mas, ao contrário, que é precisamente o conceito de vida que recolhe todas essas diferenças em uma condição ontológica básica, partilhada por todos (inclusive pelos seres humanos) na forma de uma "comunidade ontológica" articulada por uma "dimensão de continuidade subjacente à sucessão das espécies” (Barbaras, 2013, p. 270). Em outras palavras, Barbaras reconhece que, para Jonas, cada membro da vida, ou seja, cada organismo, é manifestação da vida mesma, em sua manifestação mais elementar. É precisamente aí que Jonas encontra a legitimidade que faz anunciar a legitimidade tanto do antropomorfismo quanto da própria estratégia de avaliar a vida em geral a partir do ser humano, aquele que conhece a vida de dentro, como um dos seus. Eis o sentido quase oracular da frase jonasiana, segundo a qual "a vida só pode ser conhecida pela vida” (PV, p. 115).

É como fenômeno unitário, portanto, que Jonas vê a vida e enquanto tal, a fenomenologia oferece o acesso àquela interioridade que marca toda a história evolutiva da vida na forma da liberdade, segundo as palavras de Jonas. Essa perspectiva, aliás, Barbaras reconhece, é uma tentativa de superação daquilo que ele chama de zoologia privativa, por meio de uma antropologia progressiva, que reconheça a abertura ao mundo não apenas como uma característica do Dasein, mas de toda vida animal. O próprio Dasein, nesse caso, seria reconhecido em sua raiz ontológica e em seu "modalidade de realização da existência vital, de tal modo que, ontologicamente, a existência vital tem de ser pensada a partir da vida” (Barbaras, 2013, p. 272). Esse lugar ontológico comum, portanto, fundaria o que Barbaras chama de biocentrismo ontológico jonasiano que, no limite, seria ainda marcado por um antropocentrismo metodológico, devido àquela dependência de Jonas em relação às ciências biológicas já apontada acima. Nesse sentido, Jonas estaria mais próximo de Heidegger do que ele admite.

\section{A vida como relação interior $\mathbf{x}$ interior}

Aquela afirmação que Barbaras resgatada das primeiras linhas do livro de Jonas, que reconhece a sua tarefa filosófica como uma tentativa de interpretar ontologicamente os fenômenos biológicos, deveria ser interpretada, segundo Barbaras, em dois sentidos: o primeiro, reconheceria que tal intepretação só é possível a partir da extensão de determinados níveis de interioridade aos demais seres vivos a partir do modo de existência humana, reconhecendo no humano os traços característicos de todos os demais seres o que acabaria por reduzir a própria humanidade às formas de vida descritos pela biologia, deixan- do em aberto o problema da consciência e a própria atividade racional a partir da qual ela se efetiva.

De nosso ponto de vista, Barbaras exagera o argumento e impinge a Jonas o que lá não se encontra: uma antropologia somativa que seria semelhante à metafísica clássica precisamente porque parte de uma espécie de exacerbação da importância humana em sua diferença em relação aos animais, ou seja, em sua racionalidade, fato que o retiraria em definitivo do seu fundo vital. Tal exagero argumentativo, obviamente, evoca tanto um modo próprio de interpretação quanto uma tentativa de verter sua própria argumentação a partir de uma contraposição. O problema, a nosso ver, está na confusão quase sempre despertada por Hans Jonas, em relação ao fato de que sua teria, embora tente, não teria conseguido se livrar do antropocentrismo. Ocorre que isso, para ser bem compreendido, necessita de uma revisão na teoria segundo a qual pensar a partir do humano seja, sempre, pensar antropocentricamente. Uma confusão que poderia ser evitada caso partíssemos de uma visão adequada do que seria o antropocentrismo, ou seja, não apenas uma perspectiva de centralidade do ser humano em relação às demais formas de vida, mas sobretudo uma ideia de que tais organismos estariam a seu serviço e, mais ainda, que ele está desligado de toda a história da vida pelo fato racional que lhe caracteriza. Essa segunda característica é precisamente aquela que impede que a tese de Jonas seja compreendida como antropocêntrica: embora ela reserve lugar especial ao humano no âmbito da compreensão de sua teoria, o seu objetivo é demonstrar que não há ruptura entre ele e os demais seres vivos; e isso é feito por meio daquele traço de interioridade que Jonas reconhece em seus vários níveis e que não é senão o próprio reconhecimento do fundo vital em nós mesmos, ou de nós mesmos ao fundo vital ao qual pertencem todos os demais seres. Nesse sentido, ao contrário do que aponta Barbaras, a filosofia de Jonas não está na encruzilhada entre o antropomorfismo metodológico e o biocentrismo ontológico.

Barbaras, aos poucos, evoca também contra Jonas o seu pretenso existencialismo, segundo o qual a vida poderia ser interpretada existencialmente, ou seja, a partir dos fatos biológicos que lhe são próprios e que se encontram acessíveis ao ser humano e cuja expressão seria o metabolismo. Se o ponto de partida da filosofia da vida proposta por Jonas seria, nesse caso, a "experiência de nossa vida" então, nesse caso, "não se corre o risco de conferir à vida traços que unicamente pertencem ao homem, ou pelo menos, o risco de não dispor de critério que permita isolar os traços humanos válidos também para os demais seres vivos e, assim, de justificar a afirmação de uma precessão vital?” (Barbaras, 2013, p. 276). O risco desse "antropocentrismo biológico" seria precisamente que nós inseríssemos na vida aquilo que seria apenas característica humana, "confundindo o ponto de partida ou o solo com o ponto de chegada” (Barbaras, 2013, p. 276), algo que, embora se distinguisse de um antropocentrismo metafísico ou filosófico (por seu viés biológico, ou seja, científico) permaneceria ainda antropocêntrico. O que Barbaras evoca é uma precaução que 
Jonas carece: "projetar com demasiada rapidez a interioridade de nossa existência sobre todas as formas de vida" (Barbaras, 2013, p. 276). O que Barbaras acaba por buscar, então, é uma interpretação que, no mínimo, ele reconhece como insuficiente em Jonas: uma descrição da vida que escape tanto do reducionismo quanto do antropocentrismo biológicos. A metodologia, nesse caso, não poderia se tornar uma ontologia, a fim que seja possível reconhecer traços que sejam próprios da exterioridade da vida. Caberia, em outras palavras, ao próprio ser humano, em sua capacidade racional, recolher, com modéstia, tais traços, sem que fosse necessário partir sempre de si mesmo.

A vida, como interioridade ativa, seria aquilo que fornece a Jonas a perspectiva de uma fenomenologia de tipo autocentrado, ou seja, que é feita a partir do corpo humano, aquele onde se verifica os processos típicos da vida, a começar pelo metabolismo, conceito que permite a Jonas, segundo Barbaras se distinguir da tradição espiritualista por pensar a interioridade não como uma potência, mas sempre já como ato, o que lhe possibilita pensá-la de forma integrada com a exterioridade, ou seja, com o todo dos organismos: "a vida que capto em mim pode servir para caracterizar a vida fora de mim" (Barbaras, 2013, p. 282) precisamente por essa atuação da interioridade como característica da vida. É essa atuação, aliás, que garante o processo de uma individuação ativa de todos entes vivos em sua individualidade e em seu pertencimento ao reino geral da vida, o que faria com que a "definição de ser vivo e a de individualidade sejam recíprocas" (Barbaras, 2013, p. 283), fazendo com que a vida esteja em plena relação com a exterioridade, na perspectiva daquilo que Jonas chama de transcendência da vida individual para fora de si mesma, por meio dos atos de liberdade. Aliás, se o conceito-guia de Jonas é precisamente um tal conceito, é porque ele oferece a abertura para a dinâmica própria de cada indivíduo em sua conexão com o exterior a partir de uma individualidade interior. E é precisamente dessa relação que tanto se forma um quanto o outro elemento, na medida em que a reciprocidade da relação enriquece a interioridade e, ao mesmo tempo, tal interioridade enriquecida promove maior abertura para o meio - uma abertura que é precisamente o que Jonas chama de liberdade e que se revela como uma necessidade e, ao mesmo tempo, como uma potencialização de riscos, já que quanto mais intensa a relação com o exterior, mais perigosa ela se torna. Então, é como atuação que a vida se efetiva, o que quer dizer que a "unidade do ser vivo é uma unidade por fazer, unidade de um ato, na medida em que desde o início está imensa em um elemento de exterioridade hostil que sem cessar tende a desfazê-la" (Barbaras, 2013, p. 284). A identidade, nesse caso, nasce como diferenciação em relação à realidade e tal diferença não é descontinuidade, mas uma espécie de "provocação" ativa que faz a vida aparecer como tensão entre o ser e o não-ser, como resistência àquele ato de negação. É o que Barbaras descreve como uma "dupla polaridade”: "de separação, sempre por refazer e de fusão, sempre iminente" (2013, p. 284). Eis o resultado da dependência, precariedade e fragilidade que marcam a história evolutiva da vida e cuja descrição Barbaras reconhece como um mérito de Jonas, embora insista que é necessário ainda perguntar sobre se tal descrição é satisfatória. E esta seria a "dificuldade maior" enfrentada por Jonas:

Dessa forma, em Jonas, a vida estabelece uma nova relação entre forma e matéria, porque, como forma viva, ela é "apenas uma região espaço-temporal de passagem para os materiais que temporariamente e segundo leis próprias, permanecem dentro de seus limites, e sua aparente unidade não passa de um estado configurativo da multiplicidade destes elementos transitórios" (PV, 103). Para Jonas, a vida é "a pedra de tropeço" da filosofia, porque ela é "quantitativamente um nada na incomensurabilidade da matéria cósmica" e "qualitativamente uma exceção à regra das propriedades dessa matéria" (PL, 13). Por isso, a vida deve assumir o seu lugar no corpus filosófico: "que exista a vida, e como algo assim seja possível em um mundo de pura matéria, este é o problema com que agora o pensamento terá de ocupar-se" (PL, 13). E é precisamente dessa maneira que ele assume a problemática como um ponto nodal de sua filosofia, expressa na forma de uma biologia filosófica que deve ser compreendida como um esforço por questionar não a ciência propriamente dita da biologia, pois não se trata de uma filosofia da biologia, mas precisamente, de uma biologia filosófica - ou seja, de uma pergunta sobre o modo de ser do organismo ou, nas palavras do próprio Jonas, como "a descrição de seus traços característicos, instrumentos e variedades” (M, 313). Nesse caso, trata-se não apenas de perguntar o que é a vida, mas de descrever os seus traços fundamentais e os níveis de ascensão dos elementos mais primitivos até os mais evoluídos. Isso significa que a preocupação com o Ser vivo é orientada sobretudo pela pergunta sobre o processo de sua constituição, o que implica que a vida seja pensada em sua dinâmica, como a manifestação própria e rara do ser na natureza. Tal dinâmica é marcada pela compreensão do organismo em sua "indissolúvel fusão entre a interioridade e a exterioridade" (PE, xiv), que Jonas pretende tratar como uma "contra-evidência crucial” à tradição dualista que marca a ontologia tradicional. Na pergunta sobre o organismo, portanto, encontra-se formulada a concepção do ser vivo em sua relação de precariedade e fragilidade diante do mundo, com o qual ele se relaciona a partir de uma "liberdade dialética" (PV, 106) pensada a partir dos avanços da liberdade desde graus mais inferiores até os mais superiores, como a história de um acúmulo evolutivo. Para Jonas, "a tarefa da biologia filosófica seria acompanhar o desenvolvimento desde germe de liberdade nos graus ascendentes do desenvolvimento orgânico" (PV, 107). Assim, trata-se de acentuar essa "natureza inteiramente dialética" que coloca a vida em relação com o meio, cujo resultado é a ascensão da liberdade em seus variados graus: a vida, nesse caso, é testemunha de uma relação que parte de um poder constituído a partir da necessidade (no caso do metabolismo, compreen- 
dido como o primeiro nível da liberdade orgânica, já que dá a distinção do organismo em relação à mera matéria inerte, o poder metabolizar deriva de um ter de metabolizar e se transforma em um dever de metabolizar). A existência temporal da vida depende desse duplo poder e dever, ou mais especificamente, liberdade e necessidade: "possuindo o poder, tem que exercê-lo para existir, e não pode cessar de fazê-lo sem que cesse de existir: liberdade para o fazer, mas não para o existir" (PV, 107), de tal forma que a "soberania da forma sobre a matéria é ao mesmo tempo sua sujeição à matéria”, na medida em que continua depende dela.

Essa é a relação dialética que constitui a vida e estabelece os dois polos centrais da existência orgânica descritas por Jonas por meio do "princípio da mediatez" (mediacy, Mittelbarkeit) (PL, 102), segundo o qual o acesso ao mundo que ocorre como transcendência (mediação com o mundo) que, inversamente, contribui para a "crescente individuação do ser" (PL, 100), porque "o mais complexo é também o mais individualizado" (PL, 100), a vida se arrisca sempre e cada vez mais a depender do aumento dos níveis da liberdade e, com isso, acaba se enriquecendo interiormente nos mesmos degraus da liberdade. É precisamente isso que explica, segundo Jonas, porque, em última instância, a liberdade alcança seu grau mais desenvolvido no ser humano, aquele que se torna o mais individualizado precisamente porque é também o mais carente, "o mais frágil e perecível dos seres" (para usar uma expressão de Nietzsche em Sobre verdade e mentira no sentido extramoral). Como resultado de um longo processo evolutivo, o ser humano é o indivíduo no qual a vida adquire maior complexidade, dadas as suas mediações com o meio, que incluem a atividade técnica, a artística e a racional, conforme Jonas tematiza no seu texto Ferramenta, imagem e túmulo. Do transanimal no homem. Barbaras bem nota que, para Jonas, é o risco da morte que se abre nesse horizonte de transcendência em relação ao exterior como parte da compreensão da vida como uma exposição contínua à "eventualidade do não ser” (Barbaras, 2013, p. 285).

\section{0 fechamento ao âmbito da necessidade}

Ora, Barbaras dirige sua crítica a Jonas precisamente porque, segundo ele, a teoria da projeção (segundo a qual o homem projetaria as características que encontra em si mesmo sobre os demais seres vivos), não teria solucionado a relação tensa entre interioridade e exterioridade de forma satisfatória e, nesse sentido, por mais que tenha se aproximado dela, não teria encontrado uma resposta adequada ao problema, na medida em que não consegue inaugurar uma descrição pretensamente objetiva do vivo, permanecendo então atrelado à dependência de uma descrição cujo centro é o sujeito. Estaríamos em um ciclo vicioso na medida em que "a organização mesma só é reconhecível por um ser vivo, quer dizer, de novo sobre a base de uma interpolação", entendida como relação do vivo com o seu meio (Barbaras, 2013, p. 287). Jonas teria, afinal, perma- necido dependente da polaridade subjetiva: “apesar do avanço que representa esta determinação dinâmica da interioridade, Jonas continua pensando o ato como ato de um si-mesmo mais que o si-mesmo como ato" (Barbaras, 2013, p. 288). E isso teria a ver com "certa flutuação, por não falar de incoerência, das formulações de Jonas concernentes à abertura para a exterioridade" (Barbaras, 2013, p. 300). Barbaras, contudo, dá pouca importância à evidência da interioridade como dotação do ser vivo desde os primórdios e em cuja base a ideia mesma de exterioridade se apresenta. E, mais, que esses dois polos não podem ser entendidos como isolados, mas como complementares: quanto mais a necessidade obriga à abertura do interior para a exterioridade, mais o interior se enriquece e complexifica. Essa é uma das questões mais centrais e sobre a qual Jonas mais se empenha em demonstrar. Ao insistir no fato de que Jonas acaba por falar já de uma "transcendência da necessidade" sem levar em conta que a exterioridade está já aí, efetivada sem a premissa da interioridade, Barbaras aponta um problema que o próprio Jonas parece ter reconhecido e solucionado pela recusa da bipolaridade. O mundo está aí, para o ser vivo, como uma doação, é certo. Mas tal doação só se efetiva por meio da necessidade, que é como o mundo se revela enquanto tal. Em outras palavras, querer reconhecer um mundo anterior, neutro e disponível previamente para o vivo, é recorrer a um argumento ainda ele opositor e, em última medida, dualista. É o que Jonas pretende, ele mesmo, recusar. O sujeito sensiente, o agente da necessidade, nesse caso, se descobre enquanto tal já como parte de um mundo em que a necessidade é despertada e existe enquanto tal. $\mathrm{O}$ que ela persegue não é apenas um algo posto no mundo, mas o mundo como o lugar de uma habitação ontológica que também cria a própria necessidade, que não é apenas uma característica fechada do sujeito, mas uma aspiração do próprio mundo em sua oferta de satisfação. Assim, a necessidade não é sempre seletiva, como pretende Barbaras, mas um jogo de duas faces em que ambas, mundo e organismo, o algo e a necessidade, se interpenetram. A carência, nesse caso, é um co-pertencimento. Se o mundo existe para a satisfação, ele também existe para a necessidade.

Ao contrário, Barbaras identifica em Hans Jonas precisamente a dificuldade de pensar a exterioridade enquanto tal: "com um viver que está regido pela necessidade é impossível dar conta da abertura a uma autêntica exterioridade: no movimento de satisfação da necessidade, o ser vivo não se dirige a uma autêntica alteridade" (Barbaras, 2013, p. 306). Isso porque, a relação com o outro nunca é, de fato, uma relação de alteridade: essa seria sempre, ao contrário, uma relação consigo no outro ou seja, uma relação orientada pela necessidade do ser que está fechado em si mesmo e só por isso é capaz de se dirigir ao mundo. A exterioridade é só, segundo Barbaras, uma mediação da relação consigo. Nesse sentido, Jonas não nos mostraria claramente como é possível que um ser vivo saia de si em direção à alteridade, a fim de restaurar a sua completude. Em outras palavras, Jonas não teria deixado claro 
como a exterioridade existe de fato. Nas palavras de Barbaras (2013, p. 306), "a satisfação das necessidades reclama a relação com a alteridade de um mundo, mas esta resulta, ao mesmo tempo, impensável no marco de uma filosofia que pensa o ser vivo unicamente a partir de tal satisfação". Jonas, assim, não teria alcançado a intencionalidade da consciência, porque ela deveria ser sempre abertura radical para o mundo - quando, no fundo, isso teria sido impedido pelo próprio conceito de necessidade que orienta a interpretação da vida pela via do metabolismo. Bárbaras, embora identifique tal falha, reconhece que Jonas "indica o caminho a seguir": o pensamento da vida como uma lacuna orienta a estratégia de pensá-la a partir do desejo como possibilidade de transcendência; mas uma transcendência que seja muito mais radical do que aquela proposta pelo autor de The Phenomenon of life, na medida em que se fundaria numa noção mais adequada da exterioridade.

Em um de seus textos tardios, Change and Permanence (PE, p. 240) Jonas enfrenta a questão negando precisamente a ideia de mera projeção e rejeitando o modo de resolução da problemática pela via analógica, reconhecendo que é impossível passar de "uma consciência insular para outra consciência insular”, como lembra Eric Pommier (2013, p. 48). Jonas trata, assim, de recusar a polaridade entre exterior e interior, fazendo do corpo um acesso prioritário àquilo que pode ser interpretado como interioridade no âmbito do que é mostrado, do fenômeno corporal. A questão poderia ser formulada nos seguintes termos: "a atenção aos fenômenos devem nos possibilitar reconhecer que nós não concluímos a respeito da existência de outra consciência a partir da saída de nossa própria, mas antes sobre a existência da nossa a partir do conhecimento do espírito de um outro" (Pommier, 2013, p. 48). Nesse sentido, para Jonas, nós encontramos nossas faculdades interiores apenas na comunicação com os demais organismos: "Se a compreensão original não é uma inferência, em que ela está baseada? Ela é parte de um conhecimento intuitivo da vida pela vida e isso começa pelas realizações da percepção animal, a qual está sintonizada com as realizações da expressão animal. O conhecimento de uma outra vida é um traço fundamental da relação exterior integral com o organismo animal" (PE, p. 248). A resposta de Jonas a Barbaras, assim (a qual não será desenvolvida nesse texto por razões didáticas), é formulada a partir da insistência na atividade de intercompreensão dos organismos vivos: "a vida animal é expressiva, ou melhor, ela está empenhada em se exprimir” (PE, p. 248). Os animais, por essa vida expressiva, compreendem uns aos outros de modo espontâneo e é sobre essa mesma intuição que Jonas insiste.

\section{Conclusão}

A questão central passa a ser então a questão do movimento, como medida de acesso ao mundo exterior por parte do organismo. Para Barbaras (2013, p. 307),
[...] a consciência é consciência, quer dizer, desvelamento ou manifestação, unicamente se é um desprendimento ou avanço até o que ela põe em manifesto, e uma fenomenologia do viver, restabelecido o viver em sua neutralidade originária, é necessariamente uma fenomenologia do movimento.

Nesse ponto, Barbaras acusa Jonas de não ter dado conta dessa questão central precisamente devido à sua teoria do metabolismo. Jonas seria acusado de uma irredutibilidade ontológica do movimento porque não teria explicado como se deu o surgimento do movimento do ponto de vista evolutivo. Isso porque ele é explicado, sempre, a partir de algo externo à própria essência do animal, como uma modalidade contingente. O movimento, contudo, não pode ser entendido como uma mera tentativa de satisfação das necessidades, mas como uma condição mesma do animal. Porque já é de alguma forma movimento, é que o animal pode relacionar-se com o mundo por meio da distância. É como se fosse necessário reconhecer que já existe o mundo sobre o qual organismo age. E que tal mundo não fosse apenas um objeto da necessidade. Isso significa reconhecer que o organismo já é motilidade, em sua essência, então a teoria do metabolismo de Jonas, não daria conta do problema do movimento. O que nos parece, é que Barbaras deu pouca importância para o tema da liberdade e para o fato de que Jonas, ao tentar descrever os seres vivos, o faz a partir desse conceito. Como condição mesma do organismo, a distância deixa de ser tratada como algo meramente espacial e passa ser uma distância ontológica que se abre, apenas posteriormente, para o mundo redor. A realidade é a condição do próprio vivo portanto. Não poder-se-á mais pensar um vivo interior e um vivo exterior, mas em uma co-presença de mundo no organismo e de organismo no mundo.

A argumentação de Barbaras se desenvolve de tal forma que ele chega à afirmação de que Jonas não teria escapado da ontologia da morte. Isso porque, "a vida é recuperada desde a perspectiva de sua própria negação, mais que a partir dela mesmo”, e, além disso, "a vida definida como negação da morte na exata medida em que pensa que procede de um ato original de separação “, ou seja, de separação em relação à natureza. No fim, Jonas teria permanecido dualista, medida em que foi incapaz de analisar o ser da vida em si mesmo, ou seja, de efetuar uma Epoqué da morte: "isso equivale a dizer que é preciso partir da vida do vivo e em nenhum caso de sua morte possível nem, em consequência, do mundo natural do qual se supõe que a vida surge” (2013, p. 334).

Ao insistir na questão da inter-compreensão da vida animal, ao contrário do que acentua Barbaras, Jonas recupera a vida como um fenômeno originário que escapa do mecanicismo, do materialismo e do antropocentrismo, para assentar-se sobre a relação de um ser vivo com outro ser vivo. Uma vida é sempre uma transcendência em relação a si mesma e ao mundo e, sobretudo, em relação 
aos demais seres vivos em seus corpos atuantes, a fim de identificar seus interpares e reconhecer-se neles. Trata-se, portanto, de fugir da interpolação para pensar a vida em seu fenômeno originário de um ser imediatamente expressivo, pleno de uma interioridade que se apresenta ao mundo e é captado pela vida da intuição daqueles que partilham com ele a mesma condição vital.

\section{Referências}

Barbaras, R. (2013). Introducción a uma fenomenologia de la vida. Intencionalidad y deseo. Madrid: Ediciones Encuentro.

Jonas, H. (2001). The phenomenon of life. Toward a philosophical biology. With a foreword by Lawrence Vogel. Evaston, Ilinois: Northwestern University Press.

Jonas, H. (2005). Memorias. Trad. Illana Gines Comín. Madrid: Losada.

Jonas, H. (2010). Philosophical Essays. From Ancient Creed to Technological Man. New York/Dresden: Antropos Press.

Pommier, E. (2013). Ontologie de l avie et étique de la responsabilité selon Hans Jonas. Paris: Vrin.

Jelson Roberto de Oliveira é Coordenador do Programa de Pós-Graduação em Filosofia da Pontifícia Universidade Católica do Paraná. Possui Graduação em Filosofia, Especialização em Sociologia Política e Mestrado em História da Filosofia Moderna e Contemporânea pela Universidade Federal do Paraná (1999); e Doutorado em Filosofia pela Universidade Federal de São Carlos, com pesquisa sobre a Amizade em Nietzsche. Realizou estágio pós-doutoral na Universidade de Exeter (Reino Unido), com bolsa CAPES (2016). É membro do Grupo de Pesquisa Hans Jonas do CNPq, é membro e ex-coordenador do GT Hans Jonas; membro do GT de Filosofia da tecnologia e da técnica e do GT Genealogia e crítica da ANPOF (Associação Nacional de Pós-Graduação em Filosofia). Foi professor visitante da UCM (Universidade Católica de Moçambique - 2017). É autor de "Compreender Hans Jonas" (Vozes, 2013), entre outros trabalhos incluindo livros, capítulos de livros e artigos em revistas especializadas. E-mail: jelsono@yahoo.com.br 